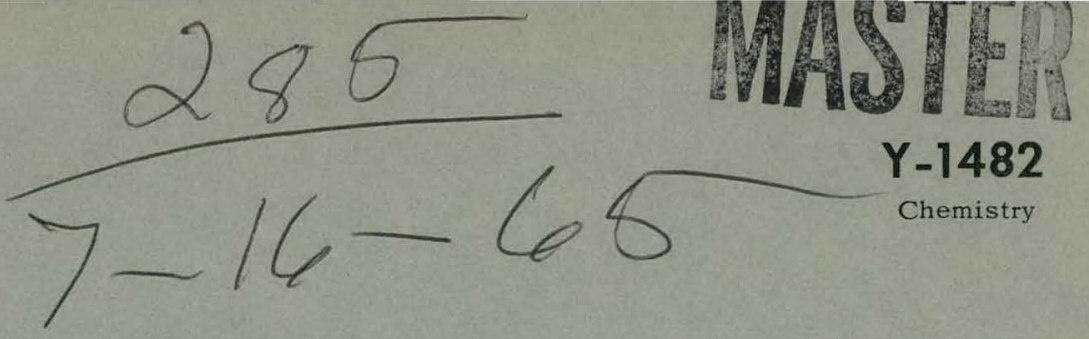

\title{
DETERMINATION OF SUBMICROGRAM QUANTITIES OF MERCURY IN LITHIUM METAL, ITS HYDRIDE, OR HYDROXIDE
}

W. C. Dietrich

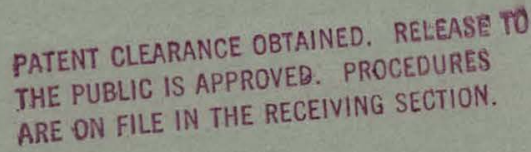

Y-12 PLANT

Oak Ridge, Tennesseo

\section{UNION CARBIDE}

\section{UNION CARBIDE CORPORATION} NUCLEAR DIVISION

Operating the

OAK RIDGE GASEOUS DIFFUSION PLANT • OAK RIDGE NATIONAL LABORATORY 


\section{DISCLAIMER}

This report was prepared as an account of work sponsored by an agency of the United States Government. Neither the United States Government nor any agency Thereof, nor any of their employees, makes any warranty, express or implied, or assumes any legal liability or responsibility for the accuracy, completeness, or usefulness of any information, apparatus, product, or process disclosed, or represents that its use would not infringe privately owned rights. Reference herein to any specific commercial product, process, or service by trade name, trademark, manufacturer, or otherwise does not necessarily constitute or imply its endorsement, recommendation, or favoring by the United States Government or any agency thereof. The views and opinions of authors expressed herein do not necessarily state or reflect those of the United States Government or any agency thereof. 


\section{DISCLAIMER}

Portions of this document may be illegible in electronic image products. Images are produced from the best available original document. 
Printed in USA. Price $\$ 2.00$. Available from the Clearinghouse for Federal Scientific and Technical Information, National Bureau of Standards, U.S. Department of Commerce, Springfield, Virginia

\section{LEGAL NOTICE}

This report was prepared as an account of Government sponsored work. Neither the United States, nor the Commission, nor any person acting on behalf of the Commission:

A. Makes any warranty or representation, expressed or implied, with respect to the accuracy, completeness, or usefulness of the information contained in this report, or that the use of any information, apparatus, method, or process disclosed in this report may not infringe privately owned rights; or

B. Assumes any liabilities with respect to the use of, or for damages resulting from the use of any information, apparatus, method, or process disclosed in this report.

As used in the above, "person acting on behalf of the Commission" includes any employee or contractor of the Commission, or employee of such contractor, to the extent that such employee or contractor of the Commission, or employee of such contractor prepares, disscminates, or provides access to, any information pursuant to his employment or contract with the Commission, or his emplayment with such contractor. 


\title{
UNION CARBIDE CORPORATION \\ Nuclear Division
}

$$
\text { Y-12 PLANT }
$$

Contract W-7405-eng-26

With the US Atomic Energy Commission

DETERMINATION OF SUBMICROGRAM QUANTITIES OF MERCURY IN LITHIUM METAL, ITS HYDRIDE, OR HYDROXIDE

\author{
W. C. Dietrich
}

Oak Ridge, Tennessee

April 1, 1965 
Report Number Y-1482

Chemistry

TID-4500 (4lst Edition)

Distribution:

Bailey, E. W.

Ballenger, H.F.

Bell, B. B.

Bernander, N.K.

Briscoe, O. W.

Burkhart, L. E.

Center, C. E. (ORGDP)

Cowen, D. D. (ORNL)

Dietrich, W. C.

Harwell, W. L. ' (ORGDP)(5)

Hemphill, L. F.

Huber, A. P.

(ORGDP)

Keller, C. A.

$(\mathrm{AEC}-\mathrm{ORO})(4)$

Kent, R. H.

Lewis, F. $O$.

(ORGDP)

McLendon, J. D.

Mitchel, G.W.

Patton, F. S.

Rowan, J. H.

Stephens, L. A.

Whitson, W. K.

Winkel, R. A. (Paducah)

$Y-12$ Central Files

$Y-12$ Central Files ( $Y-12 R C)$

In addition, this report is distributed in accordance with the category, Chemistry as given in the "USAEC Standard Distribution Lists for Unclassified Scientific and Technical Reports", TID-4500 (41st Edition), May 1, 1965. 


\section{ABSTRACT}

A method has been developed for determining submicrogram quantities of mercury in lithium metal, lithium hydride, or lithium hydroxide. Mercury was concentrated as the dithizonate from an acetate system by a dithizone-chloroform extraction, then determined spectrophotometrically as liberated dithizone after dissociating the mercury dithizonate with potassium iodide. 


\section{THIS PAGE \\ WAS INTENTIONALLY \\ ILEFT BLANK}


CONTENTS

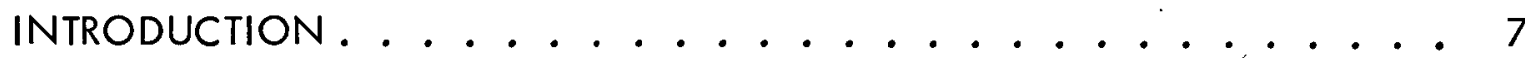

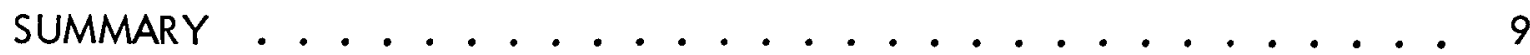

ANALYTICAL PROCEDURE ................. 11

Equipment .................... 11

Spectrophotometer................. 11

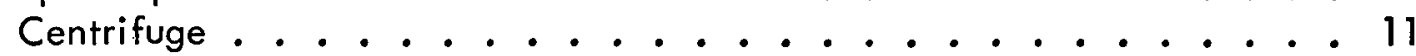

Centrifuge Bottles ................. 11

Absorption Cells ................. 11

Separatory Funnels. . . . . . . . . . . . . . 11

Water Bath . . . . . . . . . . . . . 11

Reagents. . . . . . . . . . . . . . . . 11

Dithizone Stock Solution . . . . . . . . . . . . . 11

Dithizone Working Solution. . . . . . . . . . . . 11

Reversion Reagent . . . . . . . . . . . . . 12

Lithium Acetate Stock Solution . . . . . . . . . . . 12

Chlorine Solution . . . . . . . . . . . . . 12

Hydrogen Peroxide Solution. . . . . . . . . . . . 12

Potassium Permanganate Solution. . . . . . . . . . . . 12

Hydroxylamine Hydrochloride Solution . . . . . . . . . 12

Ethylenediaminetetraacetic Acid. . . . . . . . . . . 12

Glacial Acetic Acid ................ . . 13

Mercury Stock Solution . . . . . . . . . . . 13

Mercury Working Solution ............. . 13

Absorbant Cotton ................ . . 13

Procedure ..................... . . 13

Sample Preparation ............... 13

Extraction ................... 13

Measurement .................. 13

Reagent Blank Absorbance Difference. . . . . . . . . . . 14

Calibration................... . . . 15

Experimental Study and Results . . . . . . . . . . . . 15

Discussion ................... 18

REFERENCES.................. 23 
THIS PAGE

WAS INTENTIONALLY

LEFT BLANK 


\section{INTRODUCTION}

The determination of submicrogram quantities of mercury in lithium metal, lithium hydride, and lithium hydroxide requires an analytical method of great sensitivity. A direct analysis would not be feasible because of the lack of methods of sufficient sensitivity. A possible scheme of analysis appeared to be a dithizone-chloroform extraction $(1)$ to concentrate the mercury, followed by a spectrophotometric measurement. The dithizone system could be made very specific for mercury by dissociating the mercury dithizonate with potassium iodide and measuring the liberated dithizone absorptiometrically. (2) 
THIS PAGE

WAS INTENTIONALLY LEFT BLANK 


\title{
SUMMARY
}

\begin{abstract}
,
A method has been developed for determining submicrogram quantities of mercury in lithium metal, lithium hydride, or lithium hydroxide. Mercury was concentrated as the dithizonate from an acetate system by a dithizone-chloroform extraction and determined spectrophotometrically as liberated dithizone, after dissociating the mercury dithizonate with potassium iodide.

Synthetic lithium acetate solutions were spiked with $0-6 \mu \mathrm{gs} \mathrm{Hg}(\mathrm{II})$ and analyzed for mercury (Table 2 and Figure 2). The limit of error $(0.95)$ for a single determination over this range was $\pm 0.2 \mu \mathrm{Hg}$. Based on the analysis of samples containing eight grams of lithium, the minimum detectable quantity of mercury was $0.03 \mathrm{\mu g}$ $\mathrm{Hg} / \mathrm{gm} \mathrm{Li}$.
\end{abstract}

Samples of lithium hydroxide were analyzed for mercury (Table 3). 
THIS PAGE

\section{WAS INTENTIONALLY LEFT BLANK}




\section{ANALYTICAL PROCEDURE}

\section{EQUIPMENT}

Spectrophotometer (Beckman DK-2 Ratio Recording)

Centrifugc (International, Size 2, Model V)

Centrifuge Bottles $(250 \mathrm{mls})$

Absorption Cells (two, special) (3)

Separatory Funnels (four, $125 \mathrm{mls}$, Kontes with Teflon valve; one each, 250, 500, and $1000 \mathrm{mls}$, Squibb)

Water Bath $(18 \times 12 \times 2$-inch phototray, half filled with cold water $)$

\section{REAGENTS}

Dithizone Stock Solution

To prepare this solution, dissolve $0.3 \pm 0.01$ grams of diphenylthiocarbazone in 50 milliliters of chloroform and filter the solution into a 250 -milliliter separatory funnel. Extract the dithizone from the chloroform with three 100-milliliter portions of 1:100 reagent-grade ammonia solution. Discard the chloroform layer and filter the aqueous solution into a 500 -milliliter separatory funnel through a small cotton plug. Make the filtrate slightly acid with 1:10 hydrochloric acid, add about 50 milliliters of chloroform, and extract the precipitated dithizone into the organic phase. Separate the organic phase and repeat the extraction with 20 -milliliter portions of chloroform until the color of the organic phase is a pale green. Discard the aqueous phase, combine the chloroform extracts in a 250-milliliter separatory funnel, and wash two or three times with 20-milliliter portions of reversion reagent (Page 12). Thoroughly wash the organic phase with four 50-milliliter portions of water to completely remove any reversion reagent. Transfer the purified dithizone-chloroform solution to a 500-milliliter volumetric flask and dilute to volume with chloroform. Protect the flask from light and store it in a refrigerator.

Dithizone Working Solution

Dilute two milliliters of stock dithizone solution to 500 milliliters with chloroform. Protect the solution from light and store in a refrigerator when not in use. Monitor the spectrostability of the dithizone working solution by comparing absorbance values to those of a freshly prepared solution. A significant change in absorbance indicates the need for a fresh solution. 
$\underline{\text { Reversion Reagent }}$

Dissolve $20.4 \pm 0.02$ grams of potassium acid phthalate and $60 \pm 1$ grams of potassium iodide in 1000 milliliters of distilled water. Add $1 \% \mathrm{~W} / \mathrm{V}$ sodium thiosulfate solution dropwise until the iodide solution is colorless then add two drops in excess. Extract the reversion reagent with 25 -milliliter portions of dithizone working solution until the organic phase remains green. Store over a 25 -milliliter portion of dithizone solution in a refrigerated dark bottle. Reagent is good as long as the dithizone remains green. As needed, pour out 100 milliliters into a suitable flask, add one or two drops of fresh $1 \%$ thiosulfate, and protect the solution from light.

\section{Lithium Acetate Stock Solution}

Add 920 milliliters of glacial acetic acid (Baker Analyzed Reagent) to 494 grams of lithium hydroxide monohydrate (Fisher Scientific Company) and dilute the solution to 2000 milliliters with mercury-free water. The absolute mercury content in 200 milliliters of acetate stock solution should not exceed $0.5 \mu \mathrm{gm}$. The final apparent $\mathrm{pH}$ of the solution should be $5.4 \pm 0.4$.

\section{Chlorine Solution}

Add 7.0 grams of calcium hypochlorite (Fisher Certified Reagent; $70.0 \%$ available chlorine) to 250 milliliters of water. Stir the mixture for 10 minutes and centrifuge to remove solids. Prepare fresh every day and protect the solution from light.

Hydrogen Peroxide Solution

This reagent can be prepared by adding six milliliters of $30 \%$ hydrogen peroxide (Baker and Adamson, ACS) to 200 milliliters of water. Prepare daily.

\section{Potassium Permanganate Solution}

This solution requires one gram of potassium permanganate (Baker and Adamson, Crystal) in 100 milliliters of water.

Hydroxylamine Hydrochloride Solution

Add two grams of hydroxylamine hydrochloride to 100 milliliters of water. Remove any mercury contamination by extracting this solution with the dithizone working solution.

Ethylenediaminetetraacetic Acid

By adding 4.65 grams of disodium dihydrogen ethylenediaminetetraacetic acid to 250 milliliters of water a $0.05 \mathrm{M}$ solution will be prepared. Remove any mercury contamination by extracting the solution with the dithizone working solution. 
Glacial Acetic Acid

Use Bakers Analyzed reagent-grade acid.

Mercury Stock Solution

A $1000 \mu \mathrm{gs} \mathrm{ml}$ solution will result if $0.6767 \mathrm{gram}$ of mercuric chloride is added to 500 milliliters of $1 \mathrm{~N}$ sulfuric acid.

Mercury Working Solution

Dilute 0.50 milliliter of $1000 \mu \mathrm{gs} / \mathrm{ml}$ mercury stock solution to $500 \mathrm{milliliters}$ of $0.25 \mathrm{~N}$ sulfuric acid as the diluent. This ratio gives a concentration of $1 \mu \mathrm{g} / \mathrm{ml}$.

Absorbent Cotton

Johnson and Johnson nonsterile cotton blended $50 \%$ with Safron is suitable.

\section{PROCEDURE}

\section{Sample Preparation}

Accurately weigh an aliquant of lithium sample (metal, hydride, or hydroxide) equivalent to eight grams of lithium. Finely divided metal or hydride should be pressed into a pellet. Transfer the sample to a 500-milliliter, tall-form beaker, cover with a watchglass, and place the beaker in a waterbath. Add 90 milliliters of glacial acetic acid to the metal and hydride samples. Add 50 milliliters of water to the hydroxide samples, permit the mixture to cool before slowly adding the 90 milliliters of glacial acetic acid. As the dissolution rate of the metal and hydride samples subsides, add small increments of water and swirl the contents of the beaker. Since the effect of each water increment is delayed, do not add water too rapidly. When dissolution is complete, dilute the sample with water to about 200 milliliters.

\section{Extraction}

Heat the sample solutions to $80^{\circ} \mathrm{C}$ and add two milliliters of chlorine solution. Wait five minutes, add two milliliters of hydrogen peroxide, and swirl the contents gently. Wait ten minutes and add potassium permanganate until the solution is tinted pink by an excess of one or two drops. Cool the sample and add two milliliters of hydroxylamine and one milliliter of ethylenediaminetetraacetic acid solution. Mix the contents for one minute and pour the sample into an extraction flask (one liter volumetric flask). Add as quickly as possible 20 milliliters of the dithizone working solution and vigorously agitate the contents of the flask for two minutes. Pour the mixture into a 250-milliliter centrifuge bottle, cover the bottle with a plastic cap, and centrifuge the mixture for two minutes. (If the centrifuge is not available, add 100 milliliters of water to the sample in a suitable container to facilitate phase 
separation.) Decant as much of the aqueous phase as possible from the centrifuge bottle. Wash the chloroform phase twice by refilling the bottle with water and decanting the aqueous. Transfer the mixture to a 125 -milliliter separatory funnel (Kontes), add 10 milliliters of water and shake the contents for one minute. Insert a dry cotton plug in the stem of the separatory funnel, collect the organic solution, and discard the aqueous. Reserve one half of the organic solution for the direct measurement and return the other half to the separatory funnel. Add ten milliliters of reversion agent to the separatory funnel, and shake the contents for one minute. Place a second dry cotton plug in the stem of the funnel and collect this reversed organic solution for colorimetric measurement.

\section{Measurement}

Prepare the spectrophotometer for operation according to the manufacturer's instructions. (4) Select the following spectrophotometer parameters:

$\begin{array}{ll}\text { Scale Expansion } & 2 \times \\ \text { Scanning Time } & 5 \text { minutes } \\ \text { Wavelength (initial) } & 650 \mathrm{m \mu} \\ \text { Time Constant } & 0.1 \\ \text { Sensitivity } & 10 \\ \text { Photomultiplier } & 1 \times \\ \text { Operation Selector } & \text { Absorbance } \\ \text { Operation Range } & 1-2\end{array}$

Fill the sample absorption cell with nonreversed organic solution and the reference cell with chloroform. Record the absorbance, scanning from 650 to $560 \mathrm{m \mu}$, to obtain the dithizone peak at $606 \mathrm{m \mu}$. Rinse out the sample cell with chloroform and dry by drawing air through the cell. Fill the cell with the reversed organic solution and repeat the measurement procedure. Obtain the absorbance difference between the reversed and nonreversed solutions and designate this difference as gross sample absorbance difference. Calculate the net sample absorbance difference by subtracting the reagent blank absorbance difference from the gross sample absorbance difference. Determine the mercury concentration by comparing the net sample absorbance difference to a standard curve. 


\section{Reagent Blank Absorbance Difference}

Add 20 milliliters of dithizone working solution directly to 200 milliliters of lithium acetate stock solution and extract any mercury present. Determine the absorbance difference due to mercury and designate this value as the stock solution absorbance difference as $\triangle A b_{S}$.

Add 90 milliliters of glacial acetic acid, used in the sample preparation, to another 200-milliliter aliquot of lithium acetate stock solution and follow the recommended procedure, with the exception of sample dissolution, to determine the absorbance difference due to mercury in all of the reagents plus the lithium acetate stock solution. Designate this value gross blank absorbance as $\triangle A b_{G}$.

Calculate the reagent blank absorbance difference from the following relationship:

$$
\Delta A b_{R}=\Delta A b_{G}-\Delta A b_{S}
$$

where:

$\triangle A b_{R}$ represents the reagent blank absorbance difference,

$\triangle A b_{G}$ the gross blank absorbance difference, and

$\Delta \mathrm{Ab}_{\mathrm{S}}$ the stock solution absorbance difference.

\section{Calibration}

Spike 200-milliliter aliquots of the lithium acetate stock solution with $0,1,3$, and $6 \mu$ gs of mercury. Analyze for mercury according to the procedure. The unspiked samples are to be considered as blanks. Plot net absorbance difference as a function of the mercury concentration.

\section{EXPERIMENTAL STUDY AND RESULTS}

The effect of the reagents, chlorine, peroxide, permanganate, hydroxylamine, and ethylenediaminetetraacetic acid was evaluated by comparing two different sets of synthetic samples, where Set 1 excluded these reagents. These synthetic samples were prepared by spiking 200-milliliter aliquots of lithium acetate stock solution with divalent mercury.

Mercury was then determined in both sets after direct extraction of Set I and pursuing the entire procedure for Set II. In all cases unspiked samples were considered as blanks. Tables 1 and 2 list the experimental data. 
Table 1

DETERMINATION OF MERCURY IN LITHIUM ACETATE, SET I

\begin{tabular}{ccccc}
\hline Sample & $\begin{array}{c}\text { LiAc } \\
\text { (gms) }\end{array}$ & $\begin{array}{c}\text { Hg Added } \\
(\mu g s)\end{array}$ & \multicolumn{2}{c}{ Absorbance Difference } \\
\cline { 4 - 5 } & 77.89 & & 0.040 & Gross \\
\hline 1 & 77.89 & & 0.035 & \\
3 & 77.89 & & 0.035 & \\
4 & 77.89 & 0.50 & 0.077 & 0.040 \\
5 & 77.89 & 0.50 & 0.077 & 0.040 \\
6 & 77.89 & 0.50 & 0.077 & 0.040 \\
7 & 77.89 & 1.00 & 0.122 & 0.085 \\
8 & 77.89 & 1.00 & 0.112 & 0.075 \\
9 & 77.89 & 1.00 & 0.117 & 0.080 \\
11 & 77.89 & 2.00 & 0.197 & 0.160 \\
12 & 77.89 & 2.00 & 0.202 & 0.165 \\
13 & 77.89 & 2.00 & 0.192 & 0.155 \\
\hline
\end{tabular}

Table 2

DETERMINATION OF MERCURY IN LITHIUM ACETATE, SET II

\begin{tabular}{|c|c|c|c|c|}
\hline \multirow[b]{2}{*}{ Sample } & \multirow{2}{*}{$\begin{array}{l}\text { LiAc } \\
\text { (gms) }\end{array}$} & \multirow{2}{*}{$\begin{array}{l}\mathrm{Hg} \text { Added } \\
(\mu \mathrm{gs})\end{array}$} & \multicolumn{2}{|c|}{ Absorbance Difference } \\
\hline & & & Gross & Net \\
\hline 1 & 77.89 & & 0.015 & \\
\hline 2 & 77.89 & & 0.030 & \\
\hline 3 & 77.89 & & 0.020 & \\
\hline 4 & 77.89 & & 0.020 & \\
\hline 5 & 77.89 & 0.50 & 0.070 & 0.049 \\
\hline 6 & 77.89 & 0.50 & 0.060 & 0.039 \\
\hline 7 & 77.89 & 0.50 & 0.075 & 0.054 \\
\hline 8 & 77.89 & 0.50 & 0.075 & 0.054 \\
\hline 9 & 77.89 & 1.00 & 0.110 & 0.095 \\
\hline 10 & 77.89 & 1.00 & 0.120 & 0.099 \\
\hline 11 & 77.89 & 1.00 & 0.120 & 0.099 \\
\hline 12 & 77.89 & 1.00 & 0.115 & 0.094 \\
\hline 13 & 77.89 & 3.00 & 0.310 & 0.295 \\
\hline 14 & 77.89 & 3.00 & 0.330 & 0.309 \\
\hline 15 & 77.89 & 3.00 & 0.325 & 0.304 \\
\hline 16 & 77.89 & 3.00 & 0.300 & 0.279 \\
\hline 17 & 77.89 & 6.00 & 0.625 & 0.604 \\
\hline 18 & 77.89 & 6.00 & 0.630 & 0.609 \\
\hline 19 & 77.89 & 6.00 & 0.640 & 0.619 \\
\hline 20 & 77.89 & 6.00 & 0.610 & 0.589 \\
\hline
\end{tabular}

Samples of lithium hydroxide were analyzed for mercury, and the results are reported in Table 3.

A plot of the net absorbance differences for acetate samples (Sets I and II) resulted in the linear curves shown in Figures 1 and 2. These curves exhibited comparable slopes, thus establishing the compatibility of the reagents. The limit of error $(0.95)$ for a single determination over the range $0-2 \mu \mathrm{gs} \mathrm{Hg}$ was $\pm 0.14 \mu \mathrm{g} \mathrm{Hg}$ for Set l; over the range $0-6 \mu \mathrm{gs} \mathrm{Hg}$ was $\pm 0.20 \mu \mathrm{g} \mathrm{Hg}$ for Set II. 
Table 3

ANALYSES OF LITHIUM HYDROXIDE SAMPLES FOR MERCURY

\begin{tabular}{|c|c|c|}
\hline Sample & $\begin{array}{r}\mathrm{LiOH} \\
\text { (gms) }\end{array}$ & $\begin{array}{c}\text { Hg Found } \\
(\mu g s \mathrm{Hg} / g m \mathrm{Li})\end{array}$ \\
\hline (1) & 26.71 & 124.00 \\
\hline 2 & 27.06 & 1.84 \\
\hline 3 & 27.16 & 1.55 \\
\hline 4 & 27.12 & 1.27 \\
\hline 5 & 27.72 & 2.41 \\
\hline 6 & 27.00 & 0.10 \\
\hline 7 & 27.00 & 2.04 \\
\hline 8 & 27.00 & 6.20 \\
\hline 9 & 27.00 & 1.41 \\
\hline 10 & 27.00 & 1.27 \\
\hline 11 & 27.00 & 0.11 \\
\hline 12 & 27.00 & 0.10 \\
\hline
\end{tabular}

(1) Initial material.

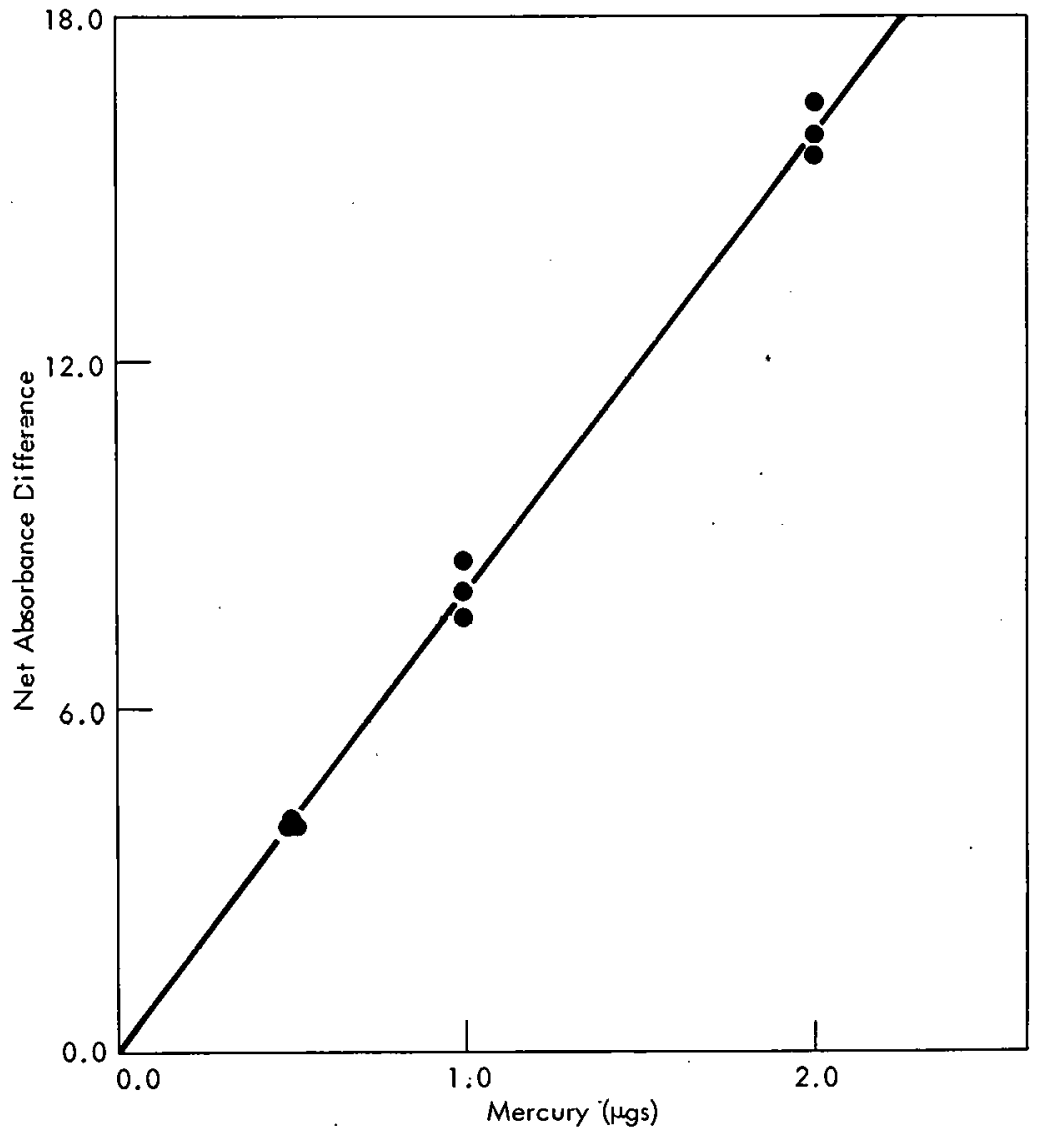

Figure 1. DETERMINATION OF MERCURY IN LITHIUM ACETATE. (Se+ I) 


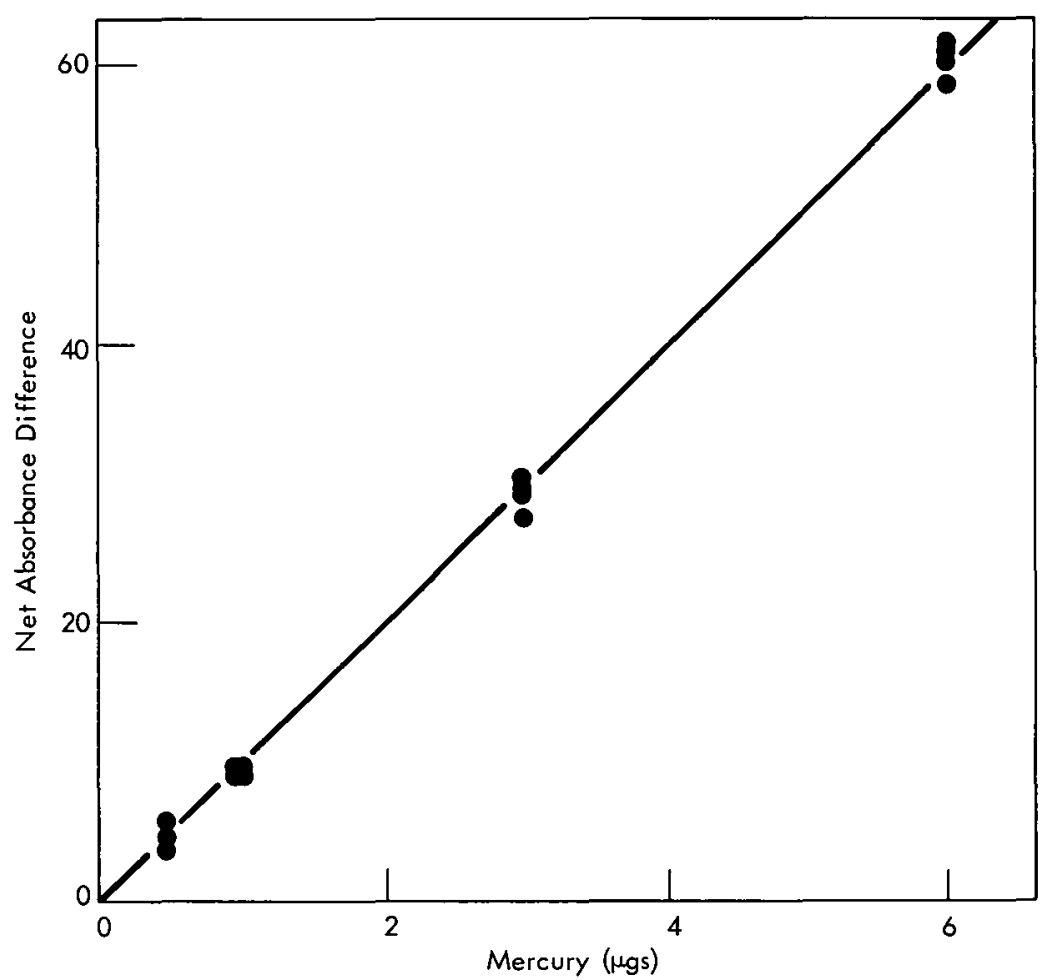

Figure 2. DETERMINATION OF MERCURY IN LITHIUM ACETATE. (Set II)

\section{DISCUSSION}

The developed method takes advantage of dithizone in chloroform as an efficient collector of submicrogram quantities of mercury. The dithizone-chloroform extraction is equivalent to a sulfide precipitation insensitivity and requires no foreign collectors or filtrations to separate mercury from the aqueous solutions. Mercury in a 200 -milliliter sample containing 77.89 grams of lithium acetate and 0.50 micrograms of mercury $(0.061 \mu \mathrm{g} \mathrm{Hg} / \mathrm{gm} \mathrm{Li})$ was readily collected by a single extraction.

The high acetate concentration of the samples resulted in relatively dense, syrupy solutions. Separation of the dithizone-chloroform phase following the extraction was facilitated by centrifugation. A sulfide precipitation would have required excessive filtration time.

Preference of an acetate system for the analysis was abetted by the moderate dissolution rate of lithium metal and hydride in glacial acetic acid, the high solubility of lithium acetate, and the low mercury content of reagent-grade glacial acetic acid. The reaction rate of lithium metal and hydride with weakly ionized glacial acetic acid was found less than with methyl alcohol which is commonly used in the decomposition of these sample types. The initial reaction decreases from moderate to slow and requires small increments of water to sustain the reaction at a practical rate. 
The final solution for analysis can be prepared, as concentrated, as two grams of lithium acetate per milliliter of water. Highly concentrated sample solutions are essential to the accumulation of sufficient mercury for analysis. The detective limit in the present routine (method) was about 0.25 micrograms mercury, absolute. With such low limits of detection it is essential that the acetic acid be pure. General reagent-grade glacial acetic acid contains about $0.50-0.80 \mu \mathrm{g} \mathrm{Hg} / 100 \mathrm{ml}$. Purification of glacial acetic acid was not attempted. However, a single dithizonecarbon tetrachloride extraction of $11 \mathrm{M}$ acetic acid resulted in a fourfold purification. Greater acid concentrations could not be used due to the increasing solubility of the carbon tetrachloride. Purified acid was not used in the present procedure.

Mercury in the sample solution could be presumed to be present as the metal, mercury (I) or mercury (II). To assure the presence of mercury(II) without subsequent interference, the solution was subjected to a series of chemical reactions involving chlorine, peroxide, permanganate, and hydroxylamine. Chlorine oxidized mercury to mercury(II), peroxide reduced excess chlorine, permanganate oxidized excess peroxide, and hydroxylamine reduced excess permanganate. Efforts to reduce chlorine directly by hydroxylamine in the acetate medium resulted in inconsistent recoveries. Potassium permanganate was unsuitable as a direct oxidant because of its reduced oxidation potential in cold solutions of low acidity. (5) Ethylenediaminetetraacetic acid (EDTA) solution was added subsequently to mask the interfering cations. Mercury (II) was separated from the aqueous solution as mercury dithizonate by extraction into chloroform. The extract was divided into two equal portions and the mercury dithizonate in one portion was dissociated with potassium iodide to release an equivalent amount of free dithizone. The absorbance of the two dithizone solutions was then measured at $606 \mathrm{m \mu}$ (Figure 3), where dithizone absorbs strongly and mercury dithizonate only weakly.

Typical absorbance scans from 650 to $560 \mathrm{m \mu}$ of dithizone-chloroform extracts from Sef II samples, Table 2, are shown in Figure 3. The absorbance differences of the dithizone solutions were compared to a standard curve for the corresponding mercury value (Figure 2). Thus, mercury dithizonate is not measured, but rather the absorbance change of free dithizone when the mercury dithizonate is dissociated by iodide is measured. This treatment is generally known as reversion. (2) The advantage of reversion is to increase the specificity for mercury. Few metal dithizonates with the exception of mercury and silver are dissociated by iodide. Silver will not form a dithizonate if the chlorides are present in an acid medium, and the reduction of chlorine in the procedure assures their presence. Further specificity was assured by the addition of EDTA.

The effect of redox reagents andEDTA in the determination of mercury was evaluated by analyzing two sets of mercury-spiked synthetic samples, where Set 1 excluded these reagents (Tables 1 and 2). A plot of net absorbance difference as a function of the mercury concentration gave a linear curve, as shown in Figures 1 and 2. The limit of error (0.95) for a single mercury determination over the ranges studied was $\pm 0.14 \mu \mathrm{g}$ mercury for Set $\mathrm{l}$, and $\pm 0.20 \mu \mathrm{g}$ mercury for Set II. No significant effect was observed due to the presence of the redox and EDTA reagents. 


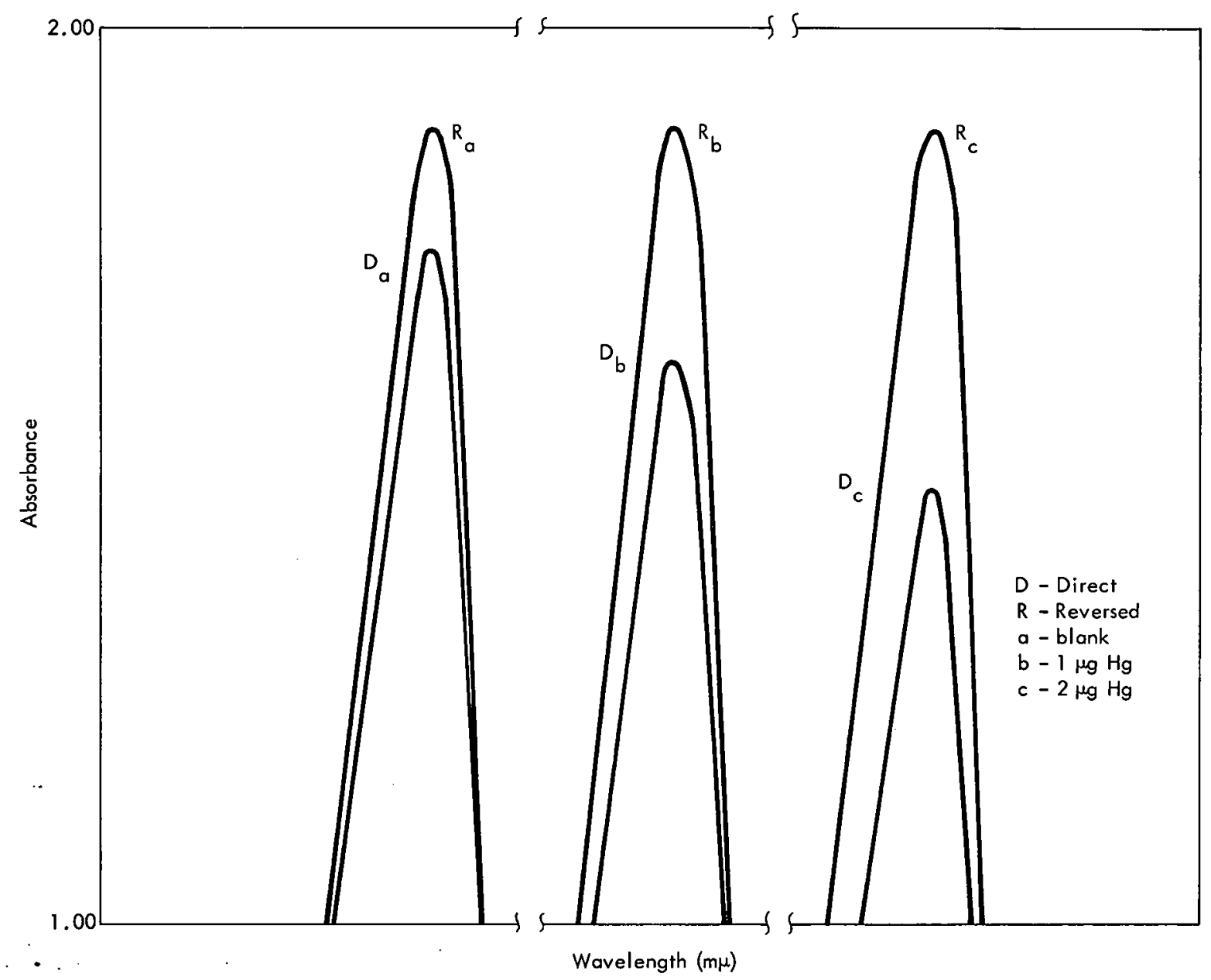

Figure 3. SCANS OF REVERSED AND NONREVERSED DITHIZONE-CHLOROFORM EXTRACTS.

Samples from batches of lithium hydroxide submitted to various schemes of decontamination from mercury, were analyzed for mercury (Table 3).

The analyst must be continuously conscious of contamination. Any mercury in the reagents must be corrected for by adequate blanks. All glassware must be dipped in nitric acid and rinsed with mercury-free water. Contamination can occur subtilely. In one instance a hand cream used by an analyst was later found to contain $3 \%$ mercury. This situation caused erratic results for several days. Careless use of reagents is especially detrimental to accurate mercury determinations. Minute residues of iodides can prevent mercury extraction; chlorine, peroxide, or permanganate will oxidize dithizone; and iodide solution used in reversion can cause negative results if unnecessarily exposed to light. Excess EDTA could also prevent the extraction of mercury.

Determination of the reagent blank is beset with several inherent difficulties. If the glacial acetic acid or lithium hydroxide monohydrate used in preparing the stock 
solution should contain mercury in an unreactive form (such as the metal), the analysis would fail to detect this mercury since the blank on the lithium acetate stock solution is determined in the absence of redox reagents. Since the reagent blank is the difference between the gross blank involving all the reagents and the lithium acetate stock solution blank, a high reagent blank would be a direct consequence of this error in the stock solution blank. In all cases during the development of the procedure, the reagent blank was consistent and never exceeded $1 \mu \mathrm{g} \mathrm{Hg} / \mathrm{gm} \mathrm{Li}$.

In the event of a high reagent blank, the acetate stock solution could be checked out by spiking the stock solution aliquot, while keeping the other reagents constant.

If the mercury contamination is not in the acetate solution, all remaining reagents must be analyzed for mercury. This step could be accomplished by a selective pairing of the four redox reagents: chlorine, peroxide, permanganate, and hydroxylamine, into the form of four simultaneous equations and solving for the contaminated reagent. Contamination in the hydroxylamine should be inconsequential since this reagent was purified by dithizone extraction. The developed method is very sensitive and relatively free from interference. The lower limit of detection $(0.02 \mu \mathrm{g} \mathrm{Hg} / \mathrm{gm} \mathrm{Li})$ might be considerably lowered by measuring mercury in the dithizone-chloroform extract by atomic absorption. 
3

THIS PAGE

\section{WAS INTENTIONALLY LEFT BLANK}




\section{REFERENCES}

(1) Sandell, E. B.; Colorimetric Determination of Trace Metals, Third Edition, p 621; Interscience Publishers, Inc, New York (1959).

(2) Irving, H., Andrew, G., and Risdon, E. J.; "Studies with Dithizone, Part I. The Determination of Traces of Mercury", J Chem Soc, 1949:541 (1949).

(3) Goldberg, G.; "Small Volume $5 \mathrm{~cm}$ Absorption Cell", Analytical Chemistry, 30, p 1163; June 1958.

(4) Beckman Instruments, Inc; Operation and Maintenance Instructions for Model DK-2 Spectrophotometer; Fullerton, California (1956).

(5) McAlpine, Roy K. and Saule, Byron, A.; Qualitative Chemical Analysis, Mercury, p 173; D. Van Nostrand Company, Inc, New York. 